\title{
AI Case Studies: Potential for Human Health, Space Exploration and Colonisation and a Proposed Superimposition of the Kubler-Ross Change Curve on the Hype Cycle
}

\author{
Matthew Williams \\ Universe Today, Canada \\ e-mail: houseofwilliams@yahoo.ca
}

\section{Martin Braddock}

Sherwood Observatory, Sutton-in-Ashfield, England, United Kingdom

e-mail:projects@sherwood-observatory.org.uk

\begin{abstract}
:
The development and deployment of artificial intelligence (AI) is and will profoundly reshape human society, the culture and the composition of civilisations which make up human kind. All technological triggers tend to drive a hype curve which over time is realised by an output which is often unexpected, taking both pessimistic and optimistic perspectives and actions of drivers, contributors and enablers on a journey where the ultimate destination may be unclear. In this paper we hypothesise that this journey is not dissimilar to the personal journey described by the Kubler-Ross change curve and illustrate this by commentary on the potential of AI for drug discovery, development and healthcare and as an enabler for deep space exploration and colonisation. Recent advances in the call for regulation to ensure development of safety measures associated with machine-based learning are presented which, together with regulation of the rapidly emerging digital after-life industry, should provide a platform for realising the full potential benefit of AI for the human species.

Keywords: artificial intelligence, regulation, healthcare, space exploration, digital afterlife.
\end{abstract}

\section{Introduction}

AI is the intelligence demonstrated by machines in contrast to natural intelligence which is displayed by human beings and other animals. Weak AI, also known as narrow AI, is artificial 
intelligence that is focused on one narrow task, for example satellite navigation. In contrast to weak AI, strong AI, also defined as broad AI, artificial general intelligence (AGI) or sentient AI is a machine with consciousness, sentience and mind and with the ability to apply intelligence to any problem, rather than just one specific task [1]. Today, all systems that use AI are operating as a weak AI focused on a narrowly defined specific problem, however, such is the advance in the field, the possibility of developing stronger if not strong AI may become a reality as computing power continues to increase and digital data is used in reinforced learning algorithms.

Alan Turing [2] defined intelligence in a very simple way as a question of conversation. He proposed that if a machine can answer any question on any subject asked of it using the same words and tone that a human being can understand, then the machine is called intelligent. This definition is known as the Turing test.

The objectives of this paper were to stimulate thinking for the assessment of the potential of AI in two areas of science and to support a philosophical argument that progression along the Kubler-Ross change curve can match the profile of new technologies defined by the hype cycle. We have chosen the areas of drug discovery and development and their application to the rapidly changing field of human healthcare and the prospects for space exploration and colonisation, both today as current examples of weak AI. However, the potential for strong AI, despite a distant goal should not be underestimated, indeed it may form part of the future for deep space exploration and colonisation of exoplanets outside of the Solar system.

\section{Definition of Life}

There are many definitions of life and we capture three which represent the most consistent:

"The condition that distinguishes animals and plants from inorganic matter, including the capacity for growth, reproduction, functional activity, and continual change preceding death" [3].

"The property or quality that distinguishes living organisms from dead organisms and inanimate matter, manifested in functions such as metabolism, growth, reproduction, and response to stimuli or adaptation to the environment originating from within the organism" [4].

"Life, living matter and, as such, matter that shows certain attributes that include responsiveness, growth, metabolism, energy transformation, and reproduction" [5].

The definition of life, as for The Turing test is anthropomorphic in nature. As the definition is usually derived from biologists, it will by inference relate traits identifiable within the life forms studied, which in turn have a common origin. This situation establishes a bias on both the observation and therefore the output. We consider parameters which support the classical definition of life today and extend the terms into a consideration of a possible future definition, making some key observations and asking several questions (Table 1). We note that that there are similarities between parameters which support the human definition of life and those which could be applied to AI.

As we begin to become less constrained by the current boundaries of human and machine intelligence and perhaps venture towards elective human enhancement in future, rather than therapeutic enhancement today, our traditional definition of life will require revisiting. Perhaps a more fitting definition of life could be: "A system which is self-sustained and able to learn and adapt to environmental input". 
Table 1. Parameter Definition of Life Today and a Proposed Future Definition

\begin{tabular}{|c|c|c|c|}
\hline Parameter & Today & Future & Key observations and questions \\
\hline Metabolism & \multirow{6}{*}{$\begin{array}{l}\text { Classical } \\
\text { definition } \\
\text { of life } \\
\text { today } \\
\text { which } \\
\text { differentiates } \\
\text { animate } \\
\text { from } \\
\text { inanimate } \\
\text { systems, } \\
\text { requiring } \\
\text { homeostatic } \\
\text { processes } \\
\text { to } \\
\text { maintain } \\
\text { longevity }\end{array}$} & $\begin{array}{l}\text { AI consumes power to } \\
\text { drive function and may } \\
\text { autoregulate power } \\
\text { consumption in future. }\end{array}$ & $\begin{array}{l}\text { Could AI develop a more efficient } \\
\text { power system autonomously? } \\
\text { Nutrition and excretion } \\
\text { components of metabolism are } \\
\text { analogous to memory resources } \\
\text { and file space used (nutrition) and } \\
\text { discarded (excretion). }\end{array}$ \\
\hline Growth & & $\begin{array}{l}\text { An algorithm can be } \\
\text { programmed to grow. AI } \\
\text { does not undergo cell } \\
\text { division but could be } \\
\text { programmed to replicate } \\
\text { at a pre-defined point. }\end{array}$ & $\begin{array}{l}\text { Viruses and AI do not have a cell } \\
\text { cycle as viruses need to infect host } \\
\text { cells to replicate. Does the } \\
\text { definition of AI resemble that of a } \\
\text { virus? }\end{array}$ \\
\hline Life cycle & & $\begin{array}{l}\text { AI may have a life cycle } \\
\text { through platforms such } \\
\text { as Alexa, Siri and the } \\
\text { Replika app. }\end{array}$ & $\begin{array}{l}\text { The life cycle may progress or } \\
\text { replicate via access of next } \\
\text { generation platforms to digital } \\
\text { data. Will this continue to be with } \\
\text { the permission of the individual or } \\
\text { organisation who generate the } \\
\text { data? }\end{array}$ \\
\hline Reproduce & & $\begin{array}{lll}\text { An algorithm can } & \text { be } \\
\text { programmed } & & \text { to } \\
\text { reproduce. } & & \end{array}$ & $\begin{array}{l}\text { A self-replicating neural network } \\
\text { has been created and a population } \\
\text { of AI agents may be able self- } \\
\text { improve through a form of natural } \\
\text { selection [6]. }\end{array}$ \\
\hline $\begin{array}{l}\text { Respond to } \\
\text { stimuli }\end{array}$ & & $\begin{array}{l}\text { Emotional intelligence is } \\
\text { rapidly evolving in } \\
\text { cameras to be able to } \\
\text { detect emotional and } \\
\text { facial expression metrics. } \\
\text { The race is on to } \\
\text { recognise individual } \\
\text { body language and tone } \\
\text { of voice and provide } \\
\text { personalised interaction. }\end{array}$ & $\begin{array}{l}\text { It is likely that AI will be able to } \\
\text { sense some forms of human } \\
\text { emotive behaviour [7] which may } \\
\text { be tuned to accommodate } \\
\text { difference in cultures. How will } \\
\text { this ability be used? }\end{array}$ \\
\hline $\begin{array}{l}\text { Adapt to } \\
\text { environment }\end{array}$ & & $\begin{array}{l}\text { Robotic AI is being } \\
\text { developed which may } \\
\text { adapt to the environment } \\
\text { to overcome obstacles. }\end{array}$ & $\begin{array}{l}\text { It is likely that AI will enable } \\
\text { drones or terrestrial robots to adapt } \\
\text { to hostile environment such as } \\
\text { earthquake zones or other areas } \\
\text { hazardous to human intervention } \\
\text { [8]. Could and should this be }\end{array}$ \\
\hline
\end{tabular}




\begin{tabular}{|l|l|l|}
\hline \multirow{2}{*}{ Evolve } & & extended into areas of conflict? \\
\cline { 3 - 4 } & $\begin{array}{l}\text { AI has been shown to } \\
\text { evolve to solve problems. }\end{array}$ & $\begin{array}{l}\text { Neuroevolution, where neural } \\
\text { networks are optimized through } \\
\text { evolutionary algorithms, is an } \\
\text { effective method to train deep } \\
\text { neural networks for reinforcement } \\
\text { learning (RL) problems [9-13]. } \\
\text { The use of simple genetic } \\
\text { algorithms has surprisingly } \\
\text { outperformed state-of-the-art RL } \\
\text { algorithms. }\end{array}$ \\
\hline
\end{tabular}

\section{Hype Cycle}

The hype cycle is a graphical representation of the maturity, adoption and application in the real world of specific technologies. It is a branded product of Gartner, a US based company dealing in consultancy and advisory activities applying information technology to the assessment of emerging trends in many technologies [14]. It has been particularly useful in the mapping and assessment of the myriad of activities which fall under the category of AI [15] and may be summarised in Amara's law which states that: "We tend to overestimate the effect of a technology in the short run and underestimate the effect in the long run" [16].

The generation of innovation and adoption of new technology will naturally be met by a variety of human response characteristics and four such categories may be represented which will drive, influence and enable both the development and deployment of new technology (Figure 1).

\section{Figure 1}

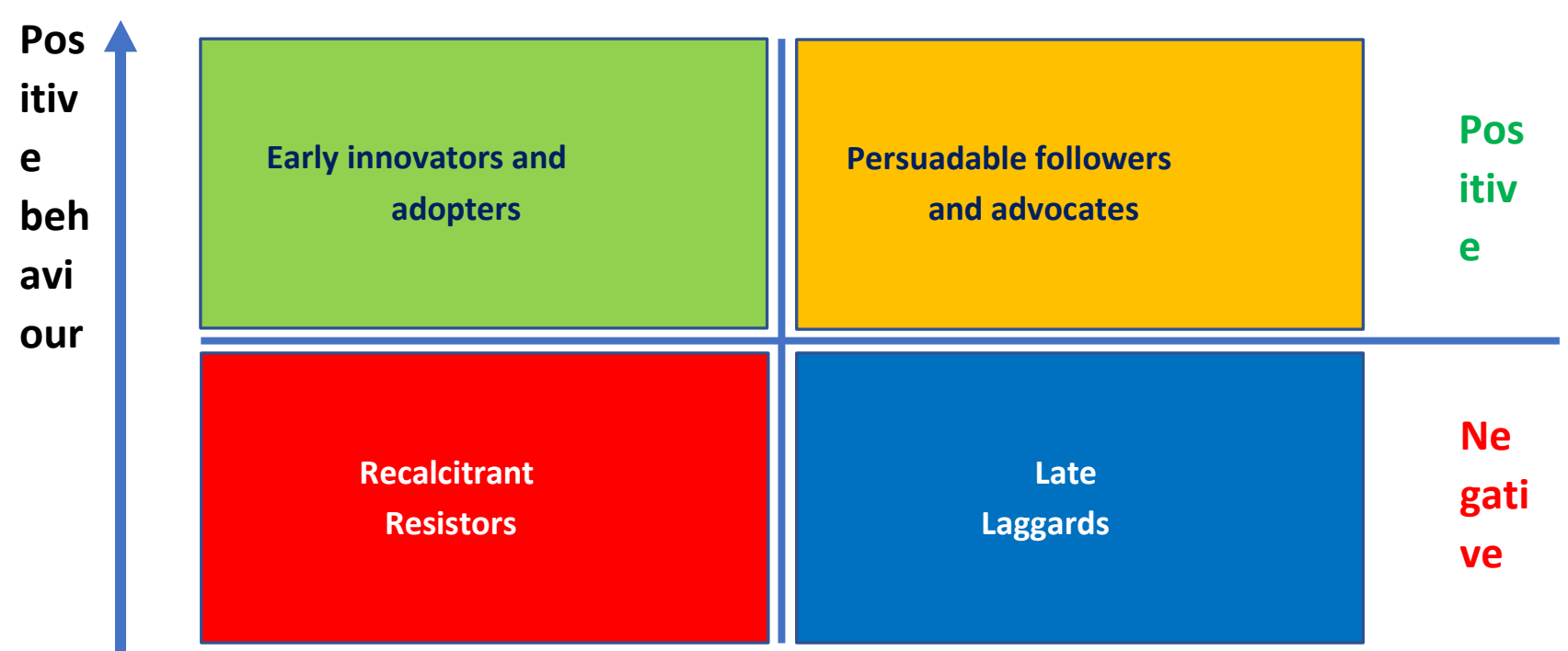

Time 
The figure may be considered in two parts; an upper positive level and a lower negative level. On the upper level. 'early innovators and adopters' are those individuals who are in the main optimistic, are entrepreneurial and have either the experience or persuasive power to be highly influential to others, especially technical experts whose skills are required. The second quadrant of positive individuals are the 'persuadable followers and advocates' who are essential catalysts for change and are likely a larger group of people. The lower level may be comprised of two quadrants. The first are the 'late laggards', who either through apathy or eventual realisation join their colleagues in progressing a concept. The last group are the 'recalcitrant resistors', who tend to be in the minority and who are resistant to new opportunities and can even be damaging to those 'persuadable followers and advocates'. This is particularly relevant when the nature of human optimism is addressed but first we should consider the human response to change.

\section{Kubler-Ross Change Curve and Criticism}

The change curve was originally proposed in 1969 by Elisabeth Kubler-Ross to illustrate and help people cope with and manage a personal terminal illness or an illness associated with a close relative or friend [17]. It is now widely used to manage dramatic change and perceived crisis, especially in larger organisations where staff experience sudden news, often associated with major restructuring [18]. By understanding both personal and personnel's response to change, understanding a person's position on the change curve may help manage the situation by retaining perspective and objectivity and ultimately bringing forward a transition of leaders and their followers to the new normale. It is not a tool without criticism and indeed in the example of coping with personal grief due to death, evidence substantiating complete transition through the change curve may be lacking [19] leading to caution in the belief that everybody completely adapts to change over time [20]. As with all change, an inherent pessimism or optimism plays a great role in retaining both personal motivation and objectivity and also in signalling the positive messages associated with change acceptance to others with whom individuals have either direct or indirect contact and communication.

\section{Change-hype and Despair Versus Hype and Hope}

Although our consideration of the hype cycle and change curve is only briefly addressed, many examples across multiple industries support both as models of human response and reaction and over time, both models allow eventual establishment of a status quo even though this may be transitory. We will consider two further factors, one example for each of the hype cycle and the change curve. The first, specific to AI is known as the AI winter and the avoidance of a second occurrence [21], [22]. The AI winter corresponds to the period at the trough of disillusionment [14] where, in this case, investor confidence and expectation, public interest and promise reached rock bottom and funding and commitment to AI technologies was drastically reduced. Many of the reasons which brought on the onset of past AI winters involved over-expectation and promise where there was and remains some concern that expectations will not be met [23] or that AI will become sentient [24]. To help put the opportunity presented by AI in perspective, a recent European Parliamentary Report exposes some of the myths and calls for a global charter to help maximise the benefits of a technology often misunderstood and misrepresented to the general public [25]. This misunderstanding is further illustrated by a report describing public perception and pessimism in long-term trends in the development of AI, though encouragingly finds optimism in a future of AI in healthcare and education [26]. This forms a segue way into the next factor which relates to personal optimism. It has been known for some years that there is a neural basis for optimism, where both optimism and pessimism are associated with different parts of the brain's cerebral hemisphere, pessimism with neurological processes in the right hemisphere and conversely, optimism with neurological processes in the left hemisphere [27], [28]. Moreover, there is evidence 
that optimists already preconceive a situation where there is probability of a future successful outcome [29] and these a priori beliefs will likely be present in individuals who reside in the upper left quadrant of Figure 1. Furthermore, unrealistic optimism though perhaps useful in conditions of high adversity, is a potential danger, particularly in the context of decision making on investment of personal or others' funds and time. Clearly individual psyche may have a major influence on esteem and personal health and well-being and directly impact the behaviour and esteem of others, particularly from a position of influence. We notice that there is a similarity in the profile of the hype cycle and the Kubler-Ross change curve and have superimposed both curves. Accepting that the axes are arbitrary and that the magnitude is for illustration purposes only, we have considered what the Kubler-Ross change curve may be for a person who is neither a natural pessimist or optimist (Figure 2a) and a natural optimist (Figure 2b).

\section{Figure 2a}

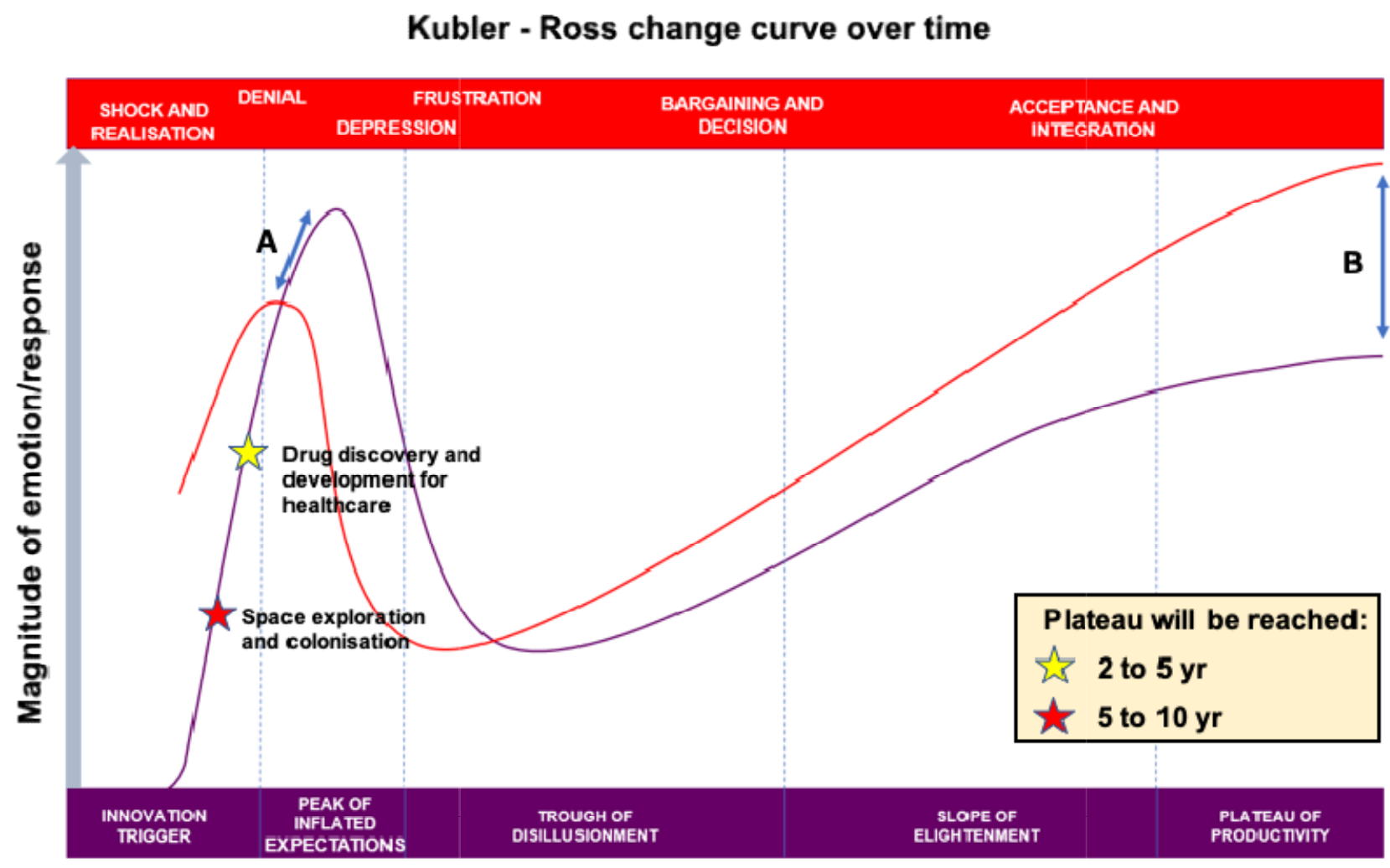

Hype cycle over time 


\section{Kubler - Ross change curve over time}

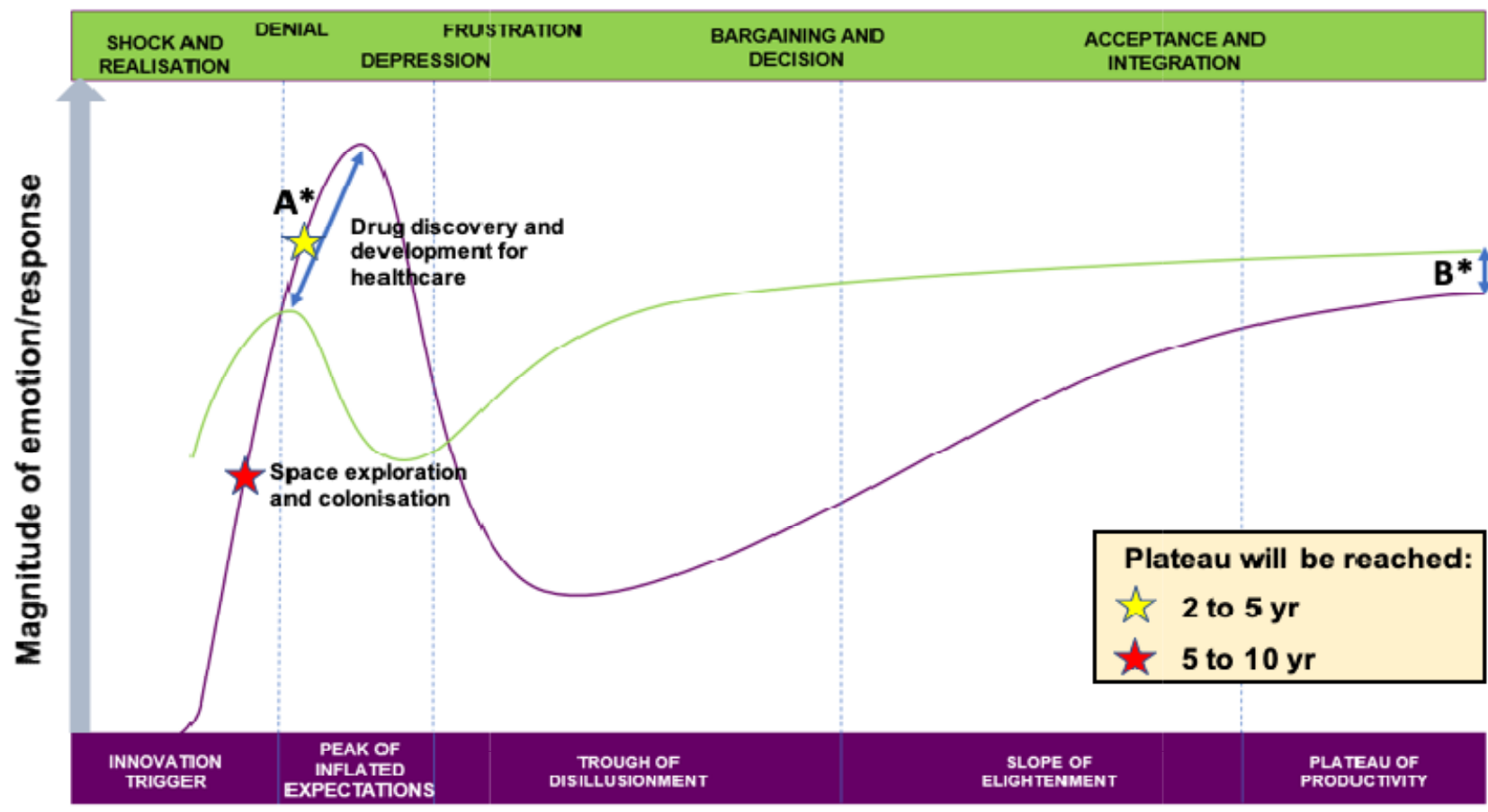

Hype cycle over time

A natural pessimist, or a person who is neither a pessimist nor an optimist may experience a rapid and steep shock behaviour where the peak of their response precedes the peak of expectation with a difference (A) and over time their acceptance and integration level is higher than at the start of their entry on the change curve with a difference magnitude (B). Compare this profile with that of a person predisposed to optimism, where their emotional experience on the change curve is blunted and flatter such that $A^{*}>A$ and the difference magnitude at the end of the cycle and curve is such that $\mathrm{B}^{*}<\mathrm{B}$. It should be noted that this is an illustrative proposal and that further qualitative work is needed to verify this concept which attempts to accommodate the natural predisposition to pessimism or optimism with the realisation and eventual acceptance of new technology.

\section{Case Study One - AI in Drug Discovery, Development and Healthcare Today}

In 2016, a study by the Tufts Centre for the Study of Drug Development estimated the overall cost of delivering a new approved and marketed medicine at $\$ 2.6 \mathrm{Bn}$ [30]. Reasons underlying productivity decline are multi-factorial and comprise contributions from basic non-clinical and translational science, clinical efficacy and safety, regulatory and commercial issues, together with the need to tackle increasingly challenging areas of human disease where the pathophysiology is often heterogeneous. Significant advances in screening [31], use of antibodies [32], [33] and generation of new modalities for targets previously thought as intractable [34], [35], phenome technologies applied to large samples sets and small volume sample size [36] mean that it is now possible to generate very large data sets designed to assist the selection of candidate drugs and their progression through lengthy and costly clinical trials. One critical part of the drug discovery process which underpins all downstream further drug development in both non-clinical and clinical phases is the physical laboratory-based manual handling of potential new medical entities and to match appropriately designed drugs to the genotype and phenotype of the patient. Drug discovery is often described using the metaphor of finding a needle in a haystack. In this case, the haystack comprises the order of $10^{60}-10^{100}$ synthetically feasible molecules [37], out of which a compound needs to be 
identified which either satisfies all the standard criteria for a molecule with drug like properties or can form a lead for further optimisation. Either way, the fraction of the total number of molecules which can be physically synthesised, let alone tested in vitro is very small and algorithm based virtual de novo design of molecules may produce a more restricted and manageable chemical library for laboratory-based work to commence or further progress.

The rapidly expanding area of machine-based learning artificial intelligence has been used to 'teach' computers the basic principles of drug design from the foundation. AI approaches to rational drug design and to predicting drug toxicology have been proposed for many years [38] and numerous approaches have been taken and reported which describe varying degrees of success [3942], with some questions remaining over the ability of AI to reproduce true chemical diversity, a prerequisite for exploitation of chemical properties aligned to delivering novelty [43]. More recently, an algorithm known as Reinforcement Learning for Structural Evolution, or ReLeaSE, is an algorithm and computer program that comprises two neural networks [44]. The networks may be regarded as a trainer and a learner network, where the trainer employs the syntax and linguistic rules for the language of chemical structures for approximately 1.7 million known biologically active molecules. This machine-based learning approach has been successful in designing compounds that fall into two broad and opposing classes of differing melting temperatures, biased towards a range of lipophilicity and with differing values of $\mathrm{pIC}_{50}$ directed against the Janus 2 nonreceptor tyrosine kinase. The system can be extended to multi-parameter optimization of compound properties in a concurrent manner and it may be possible to compress the classical lead identification and optimization phases, build into desired targets pharmacophores which may afford, for example radioprotection as standard while optimising potency, selectivity, solubility, and DMPK parameters associated with drug-likeness.

For both a pessimist and an optimist we place drug discovery, development and healthcare on the upward innovation trigger curve expecting the plateau to be reached within the next 2 to 5 years with the optimist higher up the curve.

\section{Tomorrow}

Given the driver to improve overall costs associated with research and development for new medicines and the potential of AI, there are very high expectations on the technology to shorten discovery cycle times and to align new drug design with digital data that is, or will be collected on individuals to ensure the 'right drug to the right patient taken in the right way' [45]. A rapid increase in the number of collaborations of AI technology companies with key players in the biopharmaceutical industry has occurred particularly over the last 2-3 years [46]. In addition to drug hunting and alignment to patient needs, AI also has a potential role in maximising the value of established drugs or discontinued drugs to be repurposed for the treatment of human disease for which they were not originally intended. Known as drug repurposing, this has been predominantly a serendipitous approach which has progressed well along the hype cycle having generally delivered less than expected and having been faced with numerous challenges [47]. An algorithm assisted way of predicting on-target activity in multiple disease indications and exploiting off-target activity in the same, whilst minimising both on and off-target toxicology may allow drug developers to more rapidly assemble a candidate list for clinical testing further informed by the collection of patient data. However, the potential for the contribution of AI to over promise has been recognised as 'the storm before the calm' [48].

In February 2019, it was announced that researchers have developed the largest virtual library of molecules which will soon contain over a billion molecules in a free publicly accessible pharmacology platform called ZINC and have shown that it can identify new chemotypes, some of which have very good potency and selectivity directed at their molecular target [49]. This is potentially a paradigm shift in AI assisted drug discovery and it remains to be seen whether this 
technology can be exploited to provide faster routes to drug candidate selection for clinical testing than the current industry standard.

One further area which has emerged into prominence is the field of AI assisted clinical diagnosis and management of patients, termed by Eric Topol as Deep Medicine, which may be a true partnering of AI with human intelligence and experience [50]. There can be no doubt that AI is providing substantial benefit to healthcare as the number of AI based approvals from the Federal Drug Administration is increasing and the number of indications reporting favourable predictive power for AI is also increasing. However, the paper reports that: "The state of AI hype has far exceeded the state of AI science" and provides a balanced assessment of the limitations and challenges and clear recommendations for future consideration which envisage AI as a vital assistant to the physician and not a replacement for him or her.

\section{Case Study Two - AI in Space Exploration and Colonization Today}

The development of machine learning, and artificial neural networks is also having a significant impact on space exploration. Already, space agencies like the National Aeronautics and Space Administration (NASA) and the European Space Agency (ESA) are looking to AI for assistance with data collection, data analysis, mission planning, guidance and research target selection. The first-ever case of AI being used to assist with space exploration is the Deep Space 1 probe, a technology demonstrator tasked with conducting a flyby of an asteroid (9969 Braille) and a comet (Borrelly) in 1998. This mission used an AI algorithm called Remote Agent [51], which can plan activities and diagnosing failures on-board. Since then, AI has played a major role in assisting with Earth observations and astronomical research. Examples include the Earth Observer 1 (EO-1) satellite [52], which relies on AI systems to optimize its analysis and response to natural disasters; and the Sky Image Cataloguing and Analysis Tool (SKICAT) [53], which relies on AI to assist with the classification of objects discovered by the second Palomar Sky Survey.

In addition, a team of astronomers used machine learning to sort through data gathered by the Kilo Degree Survey (KiDS) to identify 56 new possible gravitational lenses [54]. As next-generation telescopes commence operations, researchers plan to use AI to find patterns and correlations by systematic interrogation of vast amounts of gathered data. In terms of exploration, AI is already playing an important role. This includes the Autonomous Exploration for Gathering Increased Science (AEGIS), which provides automated targeting or remote sensing instruments on the Spirit and Opportunity rovers [55]; and the Planetary Instrument for X-ray Lithochemistry (PIXL), an autonomous instrument developed for the Mars 2020 rover that is designed to examine fine scale chemical variations in rocks and soils on planetary surfaces [56] - a key indicator of past (or present) life. On PIXL, John Leif Jørgensen from DTU Space in Denmark said:

PIXL's microscope is situated on the rover's arm and needs to be placed 14 millimetres from what we want it to study. That happens thanks to several cameras placed on the rover. It may sound simple, but the handover process and finding out exactly where to place the arm can be likened to identifying a building from the street from a picture taken from the roof. This is something that AI is eminently suited for [57].

Looking ahead, further developments in the field of AI are expected to have an even more significant impact. With applications ranging from navigation and enhanced situation selfawareness to decision support for spacecraft system design [52], AI is likely to play a major role in long-duration missions to Mars and other locations beyond the Earth-Moon system, especially where significant numbers of crew are involved. These missions would be characterized by crews spending months inside space capsules, where they would be subject to the effects of microgravity, higher levels of radiation and stress. Already, multiple investigations have been mounted where AI 
is envisaged as a means of mitigating these effects. For instance, in recent years, NASA has begun to explore hibernation as a viable means of keeping crews healthy during long-duration missions. In 2014, NASA partnered with Space Works Enterprises to perform an initial evaluation of a Crew Transfer Vehicle (CTV) where passengers would be placed in a torpor-induced state for the duration of the voyage [58]. The advantages of artificial hibernation extend beyond resource consumptions, aging, and psychology, and include the possibility of improved protection from cosmic radiation. This is based on recent research that relies on early animal models tests that suggest how the effects of radiation could also be reduced during hibernation [59].

Such missions, however, are likely to be heavily reliant on AI for navigation, communication, maintenance and other spaceship operations. A possible solution lies in the form of 'cognitive radio', a technology being investigated by NASA's Glenn Research Centre as a means of increasing the efficiency of space data transmissions. This approach marries advances made in machine learning and cognitive computing to radio communications to handle the heavy volume of communications traffic associated with space missions. It is easy to envision that this combination of AI and space communication could also be applied to long-duration space missions, especially where crews are kept in hibernation. Instead of relying on human controllers, AI-based systems would oversee supplying regular updates to mission controllers and selecting specific radio channels for optimum data transmission.

As Janette C. Briones, the principal investigator in the cognitive communication project, explained:

The recent development of cognitive technologies is a new thrust in the architecture of communications systems. We envision these technologies will make our communications networks more efficient and resilient for missions exploring the depths of space. By integrating artificial intelligence and cognitive radios into our networks, we will increase the efficiency, autonomy and reliability of space communications systems [60].

Navigation is another area where AI-related research is leading to applications. In 2018, NASA's Frontier Development Lab (FDL) and Intel partnered to develop a system that could assist with navigation on the Moon in the same way that a Global Position Satellite (GPS) assists with navigation on Earth. However, instead of relying on a satellite and tracking software to determine one's location, the system would rely on AI-processed images of the lunar surface. The process of creating this system consisted of using an AI to sort and combine 2.4 million images of the lunar surface, which resulted in the creation of a "virtual Moon" [61]. Based on the team's simulations, this was enough to effectively navigate in lunar environments. The team is hoping to address Mars next, using satellite and rover images of Martian surface to create a "virtual Mars." These and other maps will be incredibly useful when crewed missions are mounted to celestial bodies that do not have a system of satellites yet.

Taken together, autonomous navigation and communication systems could allow for longduration space missions where crews do not need to be awake for most of the journey. Considering that this will probably be necessary where deep-space missions are concerned (to ensure crew health and reduce the amount of supplies needed), a degree of automation is a must. In addition, AI could play a vital role in ensuring the health and well-being of crews that are kept in waking conditions during long-duration missions. A good example of this is the mobile and autonomous assistance system known as CIMON (Crew Interactive Mobile companiON). This AI assistant, which was developed by the German Aerospace Centre (DLR) in conjunction with Airbus, leverages Watson AI technology from the IBM Cloud and recent developments in robotics to create a voice-controlled artificial intelligence that is fully-autonomous and interactive.

In the summer of 2018, CIMON became the first AI to be deployed to the International Space Station, where it currently aids astronauts with their everyday tasks. Beyond this, CIMON is 
also a technology demonstrator designed to evaluate the uses of AI in mitigating the stresses of long-term spaceflight. Its effects on station operations and crew support are currently the subject of an ongoing study [62].

"CIMON is a technology demonstration of what a future AI-based assistant on the International Space Station or on a future, longer-term exploration mission would look like. In the future, an astronaut could ask CIMON to show a procedure for a certain experiment, and CIMON would do that" remarked Marco Trovatello, a spokesman of the European Space Agency's Astronaut Centre in Cologne, Germany [63]. If permanent outposts and/or colonies are created on Solar System bodies, AI-powered assistants and systems are likely to extend to these locations as well. In addition to interacting with crews and monitoring their mental and physical health, AI could be tasked with monitoring a habitat's systems, monitoring vegetable gardens, and sending regular communiques back to Earth.

As humanity's presence in space increases, and missions of greater size and complexity are mounted to locations farther into the Solar System (and possibly beyond), AI will be increasingly relied upon to handle the sheer volumes of data and to assist with complex tasks. The importance of AI in the exploration and colonization of the Solar System was perhaps best summed up by Daniela Girimonte and Dario Izzo (of the European Space Agency's Advanced Concepts Team) in their seminal 2007 study:

The return of humans to the Moon and a future manned mission to Mars therefore seem to be likely achievements we may witness in the next few decades. At the same time, even more ambitious plans and missions are being conceived by farsighted researchers who dream about the exploration and colonization of even farther planets. In the framework of these more or less concrete future scenarios, the consolidation of artificial intelligence methods in space engineering is certainly an enabling factor [52].

For both a pessimist and an optimist we place space exploration and colonisation on the upward innovation trigger curve expecting the plateau to be reached within the next 5 to 10 years with the optimist slightly higher up the curve.

\section{Tomorrow}

There is growing, if not irrefutable evidence that activities of human-kind as of approximately 12,000 years ago have increased and continue to increase extinction rates of many species and that we are experiencing the 6th extinction level event (ELE) or the Holocene extinction [64], [65]. The consequences of this latest ELE adds urgency to considering other planets to where mankind can migrate and settle, in part as a potential staging post for further exploration and in part as a fail-safe mechanism should Earth become inhospitable to supporting life as we know it today. This has been exemplified by many scientists and entrepreneurs and two of the most prominent figures are Elon Musk and the late Stephen Hawking. However, with respect to the development of AI, Musk envisages a future where AGI is developed and he has expressed grave concerns stating: "We have to figure out a way to ensure that the advent of digital super intelligence is one which is symbiotic with humanity" [66]. He goes further by saying: "That is the biggest existential crisis that we face and the most pressing one". Likewise Hawking warns: "Someone will design AI that improves and replicates itself. This will be a new form of life that outperforms humans" [67].

Despite the potential, yet theoretical concerns on the development of AGI, Musk and Hawking are joined by Astronomer Royal Sir Martin Rees, physicists Max Tegmark and Michio Kaku among many others who believe that a future for deep space exploration and colonisation to exoplanets will involve a human-hybrid avatar and that this may a logical extension of the human species [68-70]. Indeed, based on his assessment of the threat of over-population, depletion of Earth 
resources and climate change, Hawking has said: "We must continue exploring space in order to improve our knowledge of humanity. We must go beyond our humble planet" [68].

Although AGI is not in our society today, what is in our society and is a subject of considerable debate is defined by the digital after-life industry (DAI). DAI relates to the vast quantity of digital data that are and will continue to be generated at an exponential rate and could be collected and 'reconstituted' after a person dies. This is already an issue for the social platform Facebook, where it is estimated that 1.7 million people per year in the US alone will have passed away and yet their profiles will still be active [71]. The subject of data ownership is an area of intense legal debate and out of scope for this paper, however, what appears to be the case is that the technology platform rather than human person who generated the digital footprint is the owner of the data. This may have some relevance to distant space exploration as a reconstituted digital astronaut or other subject matter expert may constitute a potential future e-crew. Moreover, there is a concurrent philosophical debate on whether a digital reconstitution would have human rights and to demonstrate support for AI in the country, in 2017 a robot named Sophia was given Saudi Arabian citizenship [72]. Another more recent example relates to that of James Dunn, a 24-year-old man who died from the skin condition epidermolysis bullosa and skin cancer. With the help of Pete Trainor from the company Us ai, they were able to develop a chatbot named Bo who was able to replicate aspects of James' thoughts from many conversation James had in 'training' the bot [73]. This is one of several landmark cases which show the potential of the DAI but also seek to call for regulation so that the wishes of both those physically dead and alive are respected and that those who wish to 'live' in a virtual world are accorded the appropriate level of protection and privacy [74], [75].

More immediately, if permanent outposts and/or colonies are created on Solar System bodies, the development of AI systems and assistants is likely to extend to these locations. There are several examples of where AI is being used to make discoveries on space missions [76] where it is proposed that autonomy will be a key technology for the future exploration of our solar system and conditions are not permissible for human habitation and where robotic spacecraft may be even be out of communication with their human mission controllers [77-79].

\section{Discussion}

In this paper we have briefly considered two aspects of AI that we believe are and will continue to profoundly and positively affect science supporting human healthcare and space exploration. Like many others we can imagine a future of immense benefit and likewise one of catastrophic peril but as scientists we need to be driven by facts as we know them today. The next stage of the digital revolution is happening and is unstoppable, as was the industrial revolution and other paradigm shifts in the advancement of our species throughout the ages. Innovation and adoption of new technology, especially that likely to cause a step change for humanity requires concerted collaboration between optimists and pessimists with critical reality checking, objective communication and an understanding of risk. Let us be bold and work together across our disciplines with dialogue and open collaboration, ensure regulation is in place to understand and plan mitigation strategies and make the very best of a truly life-changing opportunity for our species on Earth and perhaps, in the not too distant future, elsewhere in the Solar System and beyond.

\section{Figure legends}

Figure 1. Proposed categorisation of individual populations and their response to and execution of change. Populations may be divided in positive and negative groups, where optimists will likely reside in the positive group.

Figure 2. Proposed superimposition of the Kubler Ross change curve on the hype cycle (purple curve) for A). Individuals who are pessimistic or neither pessimistic nor optimistic (red curve) and B). individuals who are optimistic (green curve). Indicative positions of the two case studies are 
shown on the hype cycle (yellow star $=$ drug discovery and development for healthcare; red star $=$ space exploration and colonisation). Differential peak magnitudes shown at the start $\left(\mathrm{A}, \mathrm{A}^{*}\right)$ and the end $\left(\mathrm{B}, \mathrm{B}^{*}\right)$ of the cycles and curves are proposed.

\section{References}

1. Fagella, D. What is Artificial Intelligence? An Informed Definition, Emerj, 2017, retrieved on February $16^{\text {th }} 2019$, https://emerj.com/ai-glossary-terms/what-is-artificial-intelligence-an-informeddefinition/.

2. Turing, A. M. Computing machinery and intelligence, Mind 49, 1950, pp. 433-460.

3. Definition of life in English. English Oxford living dictionaries, retrieved on February $16^{\text {th }} 2019$, https://en.oxforddictionaries.com/definition/life.

4. Life. The free dictionary, retrieved on February $16^{\text {th }} 2019$, https://www.thefreedictionary.com/life.

5. Sagan, D, Sagan, S., Margulis, L. Life biology. Encyclopaedia Brittanica, retrieved on February $16^{\text {th }} 2019$, https://www.britannica.com/science/life.

6. Chang, O, Lipson, D. Neural network quine, arXiv 1803.05859, 2018.

7. Alasaarela, D. The Rise of Emotionally Intelligent AI, Machine Learnings 2017, retrieved on

February $15^{\text {th }} 2019$, https://machinelearnings.co/the-rise-of-emotionally-intelligent-aifb9a814a630e.

8. Ghaffarzadeh, K. Mobile Robots and Drones in Material Handling and Logistics 2018-2038, IDTechEx, retrieved on February $15^{\text {th }} 2019$, http://www.idtechex.com/research/reports/mobilerobots-and-drones-in-material-handling-and-logistics-2018-2038-000548.asp.

9. Stanley, K. O., Clune J. Welcoming the Era of Deep Neuroevolution, Uber Engineering 2017, retrieved on February $17^{\text {th }}$ 2019, https://eng.uber.com/deep-neuroevolution/.

10. Lehman, J., Chen, J., Clune, J., Stanley, K. O. Safe mutations for deep and recurrent neural networks through output gradients, arXiv 1712.06563, 2018.

11. Lehman, J., Chen, J., Clune, J., Stanley, K. O. ES Is More Than Just a Traditional FiniteDifference Approximator, arXiv 1712.06568, 2018.

12. Hutson, M. Artificial intelligence can 'evolve' to solve problems, Science 2018, doi: 10.1126/science.aas9715.

13. Conti, E., Madhavan, V., Such, F. P., Lehman, J., Stanley, K. O., Clune, J. Improving exploration in evolution strategies for deep reinforcement learning via a population of noveltyseeking agents. arXiv 1712.06560, 2018.

14. Interpreting technology hype, Gartner, retrieved February $16^{\text {th }} 2019$, https://www.gartner.com/en/research/methodologies/gartner-hype-cycle.

15. Sicular, S., Brant, K. Hype Cycle for Artificial Intelligence, Gartner 2018, retrieved on February $17^{\text {th }} 2018$, https://www.gartner.com/doc/3883863/hype-cycle-artificial-intelligence-

16. Amara's law, retrieved on February $17^{\text {th }} 2018$,

https://web.archive.org/web/20180410135130/https://spotlessdata.com/blog/amaras-law.

17. Kubler-Ross, E. On death and dying, Routledge, 1969.

18. By, R. Organisational change management: a critical review, Journal of Change Management 5, 2005, pp. 369-380.

19. Corr, C. A., Doka, A. J., Kastenbaum, R. Dying and its interpreters: a review of selected literature and some comments on the state of the field. OMEGA-Journal of Death and Dying 39, 1999, pp. 239-259.

20. Stroebe, M., Schut, H., Boerner, K. Cautioning health-care professionals: bereaved persons are misguided through the stages of grief. OMEGA - Journal of Death and Dying 74, 2017, pp. 455473.

21. Russell, S. J., Norvid, P. Artificial Intelligence: A Modern Approach (2nd ed.), Upper Saddle River, New Jersey: Prentice Hall, 2003. 
22. Hendler, J. Avoiding another AI winter, Intelligent systems, IEEE 23, 2008, pp. 2-4.

23. Enwall, T. Why the pursuit of a "killer app" for home robots is fraught with peril, IEEE Spectrum 2018 retrieved on February $17^{\text {th }} 2019$,

https://spectrum.ieee.org/automaton/robotics/home-robots/why-the-pursuit-of-a-killer-app-forhome-robots-is-fraught-with-peril.

24. Turck, M. Frontier AI: How far are we from artificial 'general' intelligence, really? Retrieved on February $16^{\text {th }} 2019$, http://mattturck.com/frontierai/.

25. European Parliamentary Research Service. Should we fear artificial intelligence? European

Parliament Think Tank 2018, retrieved on February $14^{\text {th }} 2019$,

http://www.europarl.europa.eu/thinktank/en/document.html?reference=EPRS_IDA(2018)614547.

26. Fast, E., Horvitz, E. Long-term trends in the public perception of artificial intelligence, In

Proceedings of the Thirty-First AAAI Conference on Artificial Intelligence. International Joint Conferences on Artificial Intelligence, Inc., Menlo Park, CA, 2017, pp. 963-969.

27. Sharo, T., Korn, C. W., Dola, R. J. How unrealistic optimism is maintained in the face of reality, Nature Neuroscience 14, 2012, pp. 1475-1479.

28. Hecht, D. The neural basis of optimism and pessimism, Experimental Neurobiology 22, 2013, pp. 173-199.

29. Stankevicius, A., Huys, Q. J. M., Kaira, A., Series, P. Optimism as a prior belief about the possibility of future reward, PLoS Computational Biology 10, 2014, e1003605.

30. Tufts center for the study of drug development, retrieved on February $17^{\text {th }} 2019$, https://csdd.tufts.edu/.

31. Hughes, J. P., Rees, S., Kalindjian, S. B, et al. Principles of early drug discovery, British Journal of Pharmacology 162, 2011, pp. 1239-1249.

32. Marsden, C. J., Eckersley, S., Hebditch, M. et al. The use of antibodies in small-molecule drug discovery, Journal of Biological Screening 19, 2014, pp. 829-838.

33. Perez, H. L., Cardarelli, P. M., Deshpande, S., et al. Antibody-drug conjugates: current status and future directions, Drug Discovery Today 19, 2014, pp. 869-881.

34. Valeur, E., Jimonet, P. New modalities, technologies and partnerships in probe and lead generation: enabling a mode-of-action centric paradigm, Journal of Medicinal Chemistry 61, 2018, pp. 9004-9029.

35. Valeur, E., Gueret, S. M., Adihou, H., et al. New modalities for challenging targets in drug discovery, Angewandte Chemie International Edition 56, 2017, pp. 10294-10323.

36. Monte, A. A., Brocker, C., Nebert, D. W., et al. Improved drug therapy: triangulating phenomics with genomics and metabolomics, Human Genomics 8, 2014, 16.

37. Schneider, G., Fechner, U. Computer-based de novo design of drug-like molecules, Nature Reviews Drug Discovery 4, 2005, pp. 649-663.

38. Duch, W., Swaminathan, K., Meller, J. Artificial intelligence approaches for rational drug design and discovery, Current Pharmaceutical Design 13, 2007, pp. 1497-1508.

39. Olivecrona, M., Blaschke, T., Engkvist, O., Chen, H. Molecular de novo design through deep reinforcement learning, Journal of Cheminformatics 9, 2017, 48.

40. Sellwood, M. A., Ahmed, M., Segler, M. H. S., Brown, N. Artificial intelligence in drug discovery, Future Medicinal Chemistry 10, 2018, pp. 2025-2028.

41. Segler, M. H. S., Kogej, T., Tyrchan, C., Waller, M. P. Generating focused molecule libraries for drug discovery with recurrent neural networks, ACS Central. Science 4, 2018, 120-131.

42. Hessler, G., Baringhaus, K.-H. Artificial intelligence in drug design, Molecules 23, 2018, 2520.

43. Benhenda, M. ChenGAN challenge for drug discovery: can AI reproduce natural chemical diversity? arXiv 1708.08227, 2017.

44. Popova, M., Isayev, O., Tropsha, A. Deep reinforcement for drug design, Science Advances 4, 2018, eaap7855.

45. Fleming, N. How artificial intelligence is changing drug discovery, Nature 557, 2018, pp. S55S57. 
46. Mak, K.-K., Pichika, M. R. Artificial intelligence in drug development: present status and future prospects, Drug Discovery Today 2018, https://doi.org/10.1016/j.drudis.2018.11.014.

47. Pushpakom, S., Iorio, F., Eyers, P. A., et al. Drug repurposing: progress, challenges and recommendations, Nature Reviews Drug Discovery 18, 2019, pp. 41-58.

48. Jordan, A. M. Artificial intelligence in drug design - the storm before the calm? ACS Medicinal Chemistry Letters 9, 2018, pp. 1150-1152.

49. Lyu, J., Wang, S., Balius, T. E., et al. Ultra-large docking for discovering new chemotypes, Nature 566, 2019, pp. 224-229.

50. Topol, E. High-performance medicine: the convergence of human and artificial intelligence, Nature Medicine 25, 2019, pp. 44-56.

51. Havelund, K., Lowry, M., Penix, J. Formal analysis of a space craft controller using SPIN, IEEE Transactions on Software Engineering 27, 2001, pp. 749-765.

52. Daniela, G., Dario, I. Artificial intelligence for space applications, Intelligent Computing Everywhere 2007, pp. 235-253.

53. Weir, N., Fayyad, U. M., Djorgovski, G., Roden, J. The SKICAT system for processing and analysing digital imaging sky surveys, Publications of the Astronomical Society of the Pacific 107, 1995, pp. 1243-1254.

54. C. E. Petrillo, Totora, C., Chatterjee, S. et al. Finding strong gravitational lenses in the Kilo Degree Survey with convolutional neural networks, Monthly Notices of the Royal Astronomical Society 472, 2017, pp. 1129-1150.

55. Estlin, T. A., Bornstein, B. J., Gaines, D. M., et al. AEGIS automated targeting for the MER Opportunity Rover, ACM Transactions on Intelligent Systems and Technology (TIST) 3, 2012.

56. Allwood, A. et al. Texture-specific elemental analysis of rocks and soils with PIXL: The Planetary Instrument for X-ray Lithochemistry on Mars 2020, IEEE Aerospace Conference Proceedings 2015.

57. Prosser, P., Rebolledo, J. D. AI is kicking space exploration into hyperdrive-here's how, Singularity Hub 2018, retrieved on February $17^{\text {th }} 2019$, https://singularityhub.com/2018/10/07/aiskicking-space-exploration-into-hyperdrive-heres-how/\#sm.000tm2cyt1 cylenswso298wt2y6ec.

58. Bradford, J., Schaffer, M., Talk, D. Torpor inducing transfer habitat for human stasis for Mars, SpaceWorks Enterprises 2016.

59. Cerri, M., Tinganelli, W., Negrini, M. et al. Hibernation for space travel: Impact on radio protection, Life Sciences in Space Research 11, 2016, pp. 1-9.

60. Baird, D. NASA explores artificial intelligence for space communications 2017, Retrieved on February $\quad 17^{\text {th }} \quad 2019$, https://www.nasa.gov/feature/goddard/2017/nasa-explores-artificialintelligence-for-space-communications.

61. Chung, A., Ludivig, P., Potter, R. W. K., et al. Localization: or the importance of knowing where you are, Frontier Development Lab 2018, Handbook, pp. 38-39.

62. Buchheim, J., Alexander, C. Pilot Study with the Crew Interactive MObile companioN (Cimon) (Mobile Companion), Erasmus Experiment Archive 2018.

63. Pultarova, T. AI robot CIMON debuts at International Space Station, Space.com, retrieved on February $17^{\text {th }} 2019$, https://www.space.com/42574-ai-robot-cimon-space-station-experiment.html 64. Pimm, S. L, Jenkins, C. N., Abell, R., et al. The biodiversity of species and their rates of extinction, distribution and protection, Science 344, 2014, https://doi.org/10.1126/science.1246752 65. Ceballos, G., Ehrlich, P. R., Barnosky, A. D., et al. Accelerated modern human-induced species losses: entering the sixth mass extinction, Science Advances, 1(5), 2015, e1400253. 
66. Clifford, C. Musk: 'Mark my words - A.I. is far more dangerous than nukes', CNBC Make It 2018, retrieved on February $17^{\text {th }} 2019$, https://www.cnbc.com/2018/03/13/elon-musk-at-sxsw-a-iis-more-dangerous-than-nuclear-weapons.html.

67. Galeon, D. Stephen Hawking: "I fear that AI may replace humans altogether", WIRED 2017, retrieved on February $17^{\text {th }} 2019$, https://futurism.com/stephen-hawking-ai-replace-humans/.

68. Tegmark, M. Life 3.0. Being human in the age of artificial intelligence, Penguin Press, 2017.

69. Rees, M. On the future prospects for humanity, Princeton University Press, 2018.

70. Kaku, M. The future of humanity. Terraforming Mars, interstellar travel, immortality and our destiny beyond Earth, Penguin Books, 2018.

71. Evans, C. 1.7 million U.S Facebook users will pass away in 2018. The Digital Beyond 2018, retrieved on February $17^{\text {th }} 2019$, http://www.thedigitalbeyond.com/2018/01/1-7-million-u-sfacebook-users-will-pass-away-in-2018/.

72. Weisberger, M. Lifelike 'Sophia' robot granted citizenship to Saudi Arabia, Live Science, retrieved on February $15^{\text {th }} 2019$, https:/www.livescience.com/60815-saudi-arabia-citizenrobot.html.

73. De Quetteville, H. This young man died in April. So how did our writer have a conversation with him last month? The Telegraph, retrieved on February $17^{\text {th }} 2019$, https://www.telegraph.co.uk/technology/2019/01/18/will-digital-soul/.

74. Ohman, C., Floridi, L. The potential economy of death in the age of information: a critical approach to the digital afterlife industry, Minds and Machines 27, 2017, pp. 639-662.

75. Ohman, C., Floridi, L. An ethical framework for the digital afterlife industry, Nature Human Behaviour 2, 2018, pp. 318-320.

76. Chien, S., Wagstaff, K. L. Robotic space exploration agents, Science Robotics 2, 2017, eaan4831.

77. The pivotal role AI plays in the future of space travel. Ross, retrieved on February $17^{\text {th }} 2019$, https://blog.rossintelligence.com/post/ai-space-travel.

78. Campa, R., Szocik, K., Braddock, M. Why space colonisation will be fully automated, Technological Forecasting and Social Change 2019; in press.

79. Braddock, M., Campa, R., Szocik, K. Ergonomic constraints for astronauts: challenges and opportunities today and for the future, Proceedings of the International Conference on Ergonomics and Human Factors 2019, Stratford-Upon-Avon, 29 April-1 May 2019, 1st Edition. 